\title{
Controlling Product Quality at High Production Rates as Applied to BHP Billiton Iron Ore Yandi Fines Operation.
}

\author{
Proceedings, Iron Ore 2002, AusIMM, Perth 2002, pp 255-260.
}

\author{
M. Kamperman ${ }^{1}$, T. Howard ${ }^{2}$ and J.E. Everett ${ }^{3}$
}

\begin{abstract}
BHP Billiton Iron Ore has replaced the conventional product quality control batch system at Yandi with the Continuous Stockpile Management System (CSMS) centred on a fully integrated "continuous" stockpile flow from mine planning through to port reclaiming.

With increasing tonnage rates, tight operational coupling associated with the original batch system caused production interference which achieved final product quality but in an increasingly inefficient manner.

This innovative approach places a continuous emphasis on product grade control and takes full advantage of the most appropriate blending opportunities of the mine to port planning and production system in order to reduce the natural variability of the ore to an acceptable level.
\end{abstract}

To implement continuous control, product variability throughout the process is classified as long term and short term.

Long term variability is best controlled through the monthly mine planning process which determines monthly grade targets while taking into account optimum mine development. In the past, attempts to control long term variability were made at the Port through selective stockpiling and reclaiming which reduced operational efficiency.

Short term variability is best controlled around the monthly mine grade target by daily mine production scheduling, train sequencing, stacking into port stockpiles of appropriate size and systematical stockpile reclaiming.

The implementation of the new system has maintained customer accepted shipping grades and has provided significant improvements in resource utilisation, operational efficiencies and costs.

\section{INTRODUCTION}

The BHP Billiton Iron Ore Yandi Mine, established in 1991, is located approximately $260 \mathrm{~km}$ South of Port Hedland in the Pilbara region of Western Australia.

Production of the high grade pisolitic iron ore has expanded rapidly from $5 \mathrm{Mt}$ in its first year to a current annual rate of over $30 \mathrm{Mt}$. The ore produced is fully processed at the Mine as a fines product with a nominal top size of $9.5 \mathrm{~mm}$.

Mine practises, relevant to this paper, are:

- Production of fines during 2002 averaged $85 \mathrm{kt}$ per day.

- Ore is mined from four pits on $12 \mathrm{~m}$ benches. Each pit is operated with, on average, four benches and 15 floorstocks available for digging.
- Loading is via front end loaders onto haul trucks which transports the ore to one of two processing plants.

- Ore is directly fed from the haul trucks to the processing plants and crushed to finished product. The product is cone stacked onto one of two loadout stockpiles each with approximately $50 \mathrm{kt}$ live capacity.

- Ore is gravity fed directly from the cone stockpiles into rakes of 104 cars with each rake carrying $12-13 \mathrm{kt}$. An average of 7 rakes per day are railed to Port Hedland, an 8 hour journey.

Port practises, relevant to this paper, are:

- Train rakes are unloaded via one of three rotary car dumpers and stockpiled, in sequence, maintaining continuity of stacking; a 1.5 hour operation per rake.

- There are on average six live footprints available for Yandi fines with an average capacity of $200 \mathrm{kt}$.

- Stacking using travelling boom stackers is by chevron method with ply extensions at rates up to $10 \mathrm{kt} / \mathrm{h}$.

- Reclaiming is by travelling bucket wheel boom reclaimers at rates up to $10 \mathrm{kt} / \mathrm{h}$ using three longitudinal bench cuts.

- Pilgrim step reclaiming lengths are varied according to individual shipment requirements to ensure representative cuts from each bench.

- Blending between stockpiles is carried out for grade reasons only under exceptional circumstances.

Sampling of product is summarised as follows:

At the Mine:

- No laboratory facilities exist on-site. All samples are prepared on site and conveyed to Newman for analysis with an average turn-around time of 24 hours.

- All blast holes are manually sampled from the cone. Results are used to block floorstocks into mineable areas of similar grade.

- Product sampling takes place for sizing control only. Train grade estimates are determined from floorstock block grades using a tonnage-grade mass balance through a simple loadout model.

At the Port:

- All rakes are sampled at stacking by taking an average of 12 primary cuts per hour. Rake results are combined by tonnage-grade mass balance to determine stockpile grades.

- At shiploading, sub-gross samples representing approximately $15 \mathrm{kt}$ are collected. These results are combined by tonnage-grade mass balance to provide the grade of a shipment. 
(1) Superintendent Planning, BHP Billiton Iron Ore, PO Box 231, Port Hedland, WA 6721.

(2) Manager Business Improvement, BHP Billiton Iron Ore, PO Box 655, Newman, WA 6753.

(3) Centre for Modelling Management Systems, The University of Western Australia.

\section{GRADE CONTROL HISTORY AND THE BATCH SYSTEM}

Mining operations at Yandi were originally set up as a single pit with a conventional batch grade control system aimed at achieving $200 \mathrm{kt}$ of mined ore on grade. This proved to be adequate in the early years of the operation. However, in order to maintain high product quality with increasing production rates, operational inefficiencies occurred at both the Port and Mine using the batch system.

In late 1999, it was concluded that the conventional batch system at Yandi was no longer a cost efficient product quality control tool.

The reasons were:

- At increased tonnage rates the effectiveness of the batch system was highly dependent on strong operational coupling between mine and port, which on occasions required significant operational interference.

- It was increasingly difficult to match the start of a batch with a stockpile build at the Port. The variability of grade within a batch caused uncertainty at the Port resulting in selective building and reclaiming of stockpiles to guarantee on-grade shipments. To overcome this problem the Mine then endeavoured to get each train "on grade". As tonnages increased the combination of these actions were directly affecting mining, stacking and shiploading rates.

- The batch system did not readily allow full optimisation of the resource from multiple pits of diverse grades due to short term nature of grade constraints. Increasing use of precrusher stockpiles resulted, particularly when opening up new pits.

- The batch system placed non-uniform importance on grade control. At the start of the batch, grade was not usually considered as important as at the end because of perceived opportunities to fix a problem later in the batch.

- At high and continuous tonnage rates "flow-on corrective effects" from the end of one batch passed on to the start of the next batch. This was compounded by a 48 hour time interval between mine production scheduling, stacking and sampling of the resulting ore at the Port.

- The batch system tends to allow different approaches to grade control by different grade controllers. With increasing tonnages this became prone to errors, especially in a high tonnage continuous operation using a commuter based manning system.

Following on from the successful development and implementation of the Continuous Stockpile Management System (CSMS) for the Newman JV mines (Everett and Kamperman, 1999), it was concluded that a system based on similar principles would be developed for the Yandi fines product to replace the batch system.

The development has taken place over two years utilising mine and port production personnel and the Centre for Modelling Management Systems at the University of Western Australia. A staged approach was used:
1. At the Mine the focus of grade control was moved to the Mine face where previously it was centred on trains.

2. The daily scheduling decision support system based on monthly mine targets was fully developed and implemented at the Mine.

3. Stockpile size changes and CSMS rules were implemented at the Port.

\section{CONTINUOUS STOCKPILE MANAGEMENT SYSTEM}

\section{Definition}

The Continuous Stockpile Management System is a fully integrated production and grade control system from mine planning through to port reclaiming. Central to the process is an exponentially smoothed "continuous" stockpile flow with no nominal beginning or end.

The key objective is to achieve on-grade shipments, at lowest cost, by optimum blending from pits with diverse resource grades utilising a flexible mining system and a disciplined approach to railing, stacking and reclaiming.

The following goals were developed for the system:

- Control of product grade is moved to the steps in the production process best suited to achieve quality at least cost.

- The most cost efficient "in-process" blending is utilised to achieve the final product variability.

- Operational decoupling occurs as much as practical within the constraint of grade control; specifically:

- Each pit produces to an optimum resource plan with minimal disruption.

- Port stacking rates are not inhibited.

- Shiploading rates are not compromised.

- Sampling to take place only where it adds value to the process and to a high standard.

\section{Long and short term variability}

Important to the successful implementation of the CSMS is the recognition of long and short term variability. In the process long term variability can be observed on a monthly basis, whereas short term variability is observed over two to three days. Short term variability tends to be stable around the long term

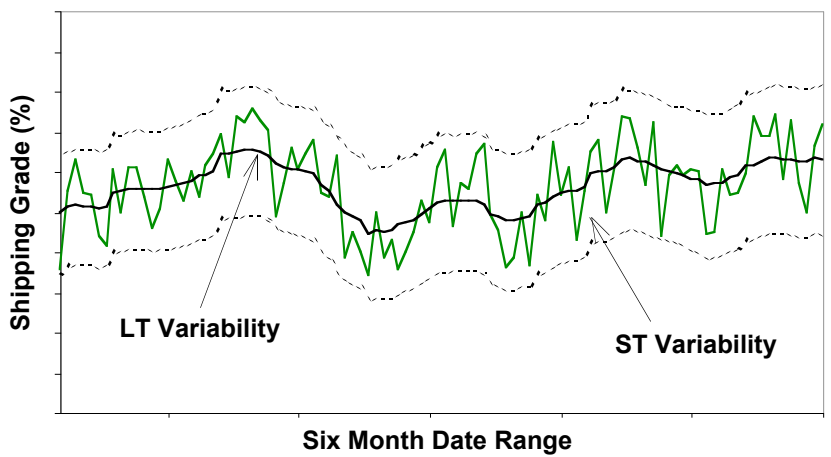

variability (Figure 1). 
Figure 1. Illustration of long term (LT) and short term (ST) variability for actual shipping grades.

The measures and importance of each step of the CSMS to control long and short term variability are illustrated in Table 1.
Long term variability is most effectively controlled by the monthly mine planning processes and adherence to the plan. Short term variability is most effectively controlled by daily mine scheduling and mining methods, railing sequences, stacking and reclaiming methods.

Table 1. Variability analysis of Yandi CSMS.

The measures used to control short term variability are not

\begin{tabular}{|c|c|c|c|}
\hline Variability Type & $\begin{array}{c}\text { Monthly Mine } \\
\text { Planning }\end{array}$ & $\begin{array}{c}\text { Floorstock } \\
\text { Management }\end{array}$ & Da \\
\hline \multicolumn{4}{|l|}{ Long Term } \\
\hline \multicolumn{4}{|l|}{ Short Term } \\
\hline & Darker shades & dicate higher degrees & finfl \\
\hline Comments & $\begin{array}{l}\text { Resource } \\
\text { optimisation in line } \\
\text { with mine } \\
\text { development } \\
\text { requirements } \\
\text { results in monthly } \\
\text { grade target. } \\
\text { Entire CSMS } \\
\text { aligned with } \\
\text { monthly grade } \\
\text { target. }\end{array}$ & $\begin{array}{l}\text { Floorstock } \\
\text { availability aligned } \\
\text { with monthly } \\
\text { development plan } \\
\text { for each pit with } \\
\text { requirement to } \\
\text { achieve grade target } \\
\text { throughout the } \\
\text { month. }\end{array}$ & $\begin{array}{l}\text { Dai } \\
\text { smo } \\
\text { devi } \\
\text { grac } \\
\text { Incl } \\
\text { corr } \\
\text { port } \\
\text { bias }\end{array}$ \\
\hline
\end{tabular}

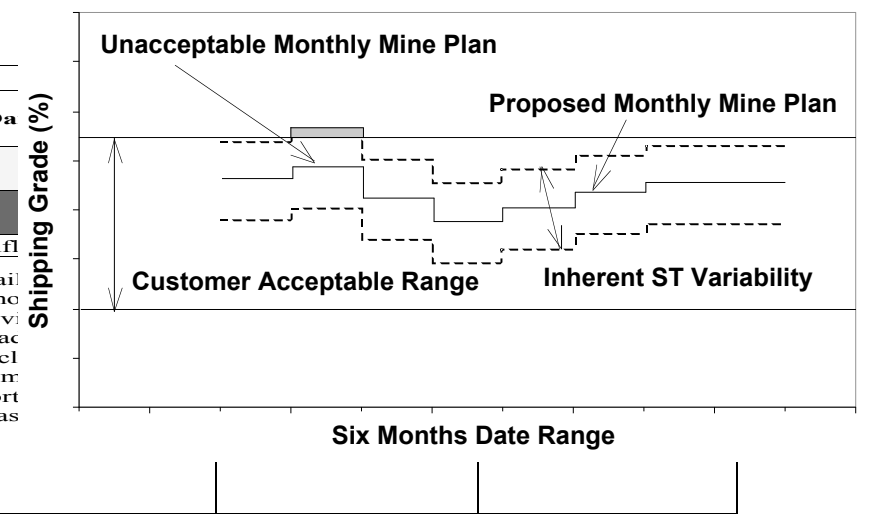

\begin{tabular}{|c|c|c|c|c|c|}
\hline \multirow[b]{2}{*}{ Variability Type } & \multirow{2}{*}{$\begin{array}{l}\text { RAIL } \\
\text { Railing }\end{array}$} & \multicolumn{4}{|c|}{ PORT } \\
\hline & & Dumping & Stockpiling & Reclaiming & Ship Loading \\
\hline \multicolumn{6}{|l|}{ Long Term } \\
\hline \multicolumn{6}{|l|}{ Short Term } \\
\hline \multicolumn{6}{|c|}{ Darker shades indicate higher degrees of influence on the control of variability } \\
\hline Comments & $\begin{array}{l}\text { Trains from } \\
\text { alternate load-outs } \\
\text { are maintained in } \\
\text { sequence } \\
\text { throughout the rail } \\
\text { cycle. }\end{array}$ & $\begin{array}{l}\text { Maintain mine } \\
\text { departure sequence } \\
\text { of rakes through } \\
\text { dumping. }\end{array}$ & $\begin{array}{l}\text { Continuity of } \\
\text { stacking to } \\
\text { optimum size using } \\
\text { Chevron - ply } \\
\text { method for control } \\
\text { of short term } \\
\text { variability. }\end{array}$ & $\begin{array}{l}\text { Priority given to } \\
\text { three bench } \\
\text { reclaiming with } \\
\text { pilgrim step } \\
\text { lengths aligned } \\
\text { with cargo size. }\end{array}$ & $\begin{array}{l}\text { No interference } \\
\text { with ship loading } \\
\text { for grade control } \\
\text { reasons under } \\
\text { normal grade } \\
\text { conditions. }\end{array}$ \\
\hline
\end{tabular}

efficient for the control of long term variability and vice versa. For example, the control of long term variability using short term control measures such as preferential floorstock mining and precrusher stockpiling, selective rake stacking or blending between port stockpiles during shiploading results in significant operational inefficiencies.

\section{CONTRIBUTIONS TO THE CONTINUOUS STOCKPILE MANAGEMENT SYSTEM}

\section{Mine}

\section{Monthly mine planning}

With respect to CSMS monthly mine planning ensures:

- Maximum utilisation of the resource within the constraints of the allowable grade variability.

- Control of long term variability within a range that enables shipments within customer acceptable ranges, taking into account short term variability (Figure 2).

- Availability of a range of floorstocks to consistently achieve the monthly mine plan target grade throughout the month.

- Mining is continuously focussed on on-grade shipping.

To ensure short term variability measures are not used to control long term variability, the monthly mine plan defines the target for daily control throughout the entire operation for the month.

Figure 2. Monthly mine plan variability.

\section{Daily mine scheduling and mining}

With respect to CSMS daily mine scheduling and mining ensures:

- Continuous emphasis on achieving on-grade port stockpiles.

- Daily mining operations are consistent with the monthly mine plan.

- Pit development is continuously accommodated within the constraints of grade control.

- The load and haul process is cost efficient within the constraints of grade control and initial limited blending.

- The use of short term pre-crusher stockpiles is eliminated.

- Grade biases between port and mine estimates are taken into account during mine scheduling.

At Yandi, daily mine scheduling is carried out with the assistance of an Excel-based decision support system. 
Features of the system include:

- Decision support rather than decision making. The Grade Controller sets up system constraints to take into account day-to-day operational restrictions and objectives.

- All four pits are treated as a single ore source, but are mined to individual resource targets and development objectives.

- All available floorstocks within the constraints of operational priorities are considered equally in determining the 24 hour blend.

- Floorstock block grades derived from blasthole sampling are used in the decision support system.

- Upper and lower control limits aligned with shipping tolerances are used as a basis of decision making.

- System output is recommended mining over a 24 hour period expressed as number of truck loads from individual available floorstock blocks.

- The system takes into account grade estimates of mined ore on loadouts and in trains on track when making its recommendations. The best grade estimate available at the time is used in decisionmaking.

- Port sampling grades for stacked trains are incorporated into the system as soon as practical (approximately 48 hours after production scheduling process).

- Port to mine grade bias adjustments are determined through continuously smoothed train grade reconciliations for each loadout.

- Before making scheduling recommendations all ore in the floorstocks and on loadout stockpiles are adjusted for the most recent bias result.

The short term scheduling decision support system uses three principles: Exponential Smoothing, minimisation of Total Grade Stress, and the Continuous Stockpile Model which are described below.

\section{Exponential Smoothing}

Exponential smoothing is widely used to summarize and forecast data (Hanke \& Reitsch, 1998).

The principle reasons for using this technique in the Yandi CSMS are:

- A grade model is created which predicts the probability of achieving on-grade shipments while taking in account the contribution of all in-process ore.

- Allows interpretation of trends in complex data with relatively low precision, as in the case of rake estimates.

- The most recent production is given a higher contribution to the smoothed value.

- The contribution of ore decreases exponentially with time in the process, and not suddenly as in moving averages.

- Ease of computation.

In the short term scheduling decision support system, exponential smoothing is used to calculate a smoothed grade based on sequential train data (Figure 3), ore on the loadouts and in trains on track.

The grade from successive production steps is multiplied by an exponentially decreasing factor depending on its position in the sequence and its relative tonnage. The resulting numbers from these calculations are added to give a smoothed grade.

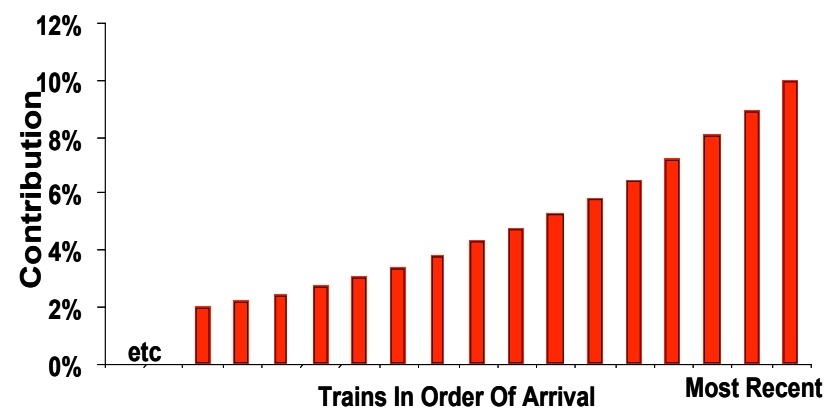

Figure 3. Example of contributions of sequential train grade data to smoothed value $(\square=0.1)$.

The calculation to generate exponentially smoothed data is:

$$
\mathrm{S}_{\mathrm{t}}=\square * \mathrm{~V}_{\mathrm{t}}+(1-\square) * \mathrm{~S}_{\mathrm{t}-1}
$$

where $\mathrm{S}_{\mathrm{t}}$ is the current smoothed value, $\mathrm{S}_{\mathrm{t}-1}$ is the previous smoothed value, $V_{t}$ is the grade of the most recent step in the production process, and $\square$ is the smoothing constant.

A larger value for $\square$ gives more emphasis to recent data, and its influence dies away quicker (Figure 4).

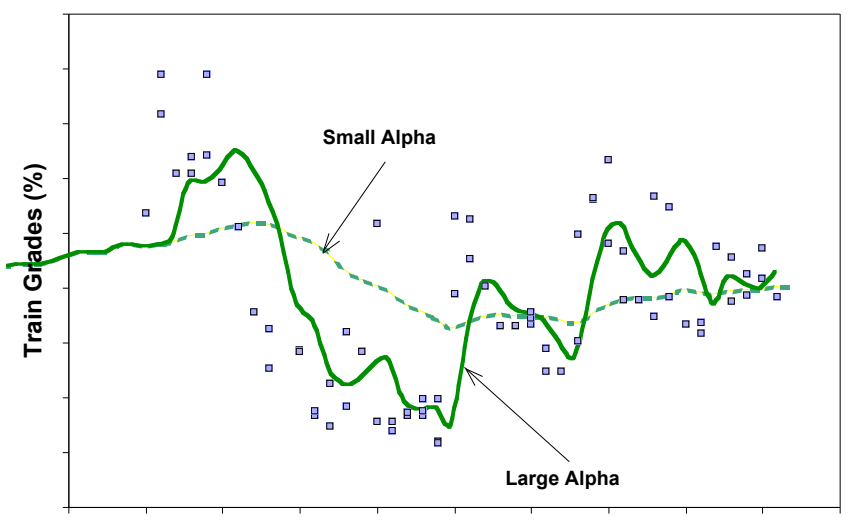

One Month Date Range

Figure 4. Effect of alpha $(\square)$ on degrees of exponential smoothing.

Simulation studies of production data collected over many months have identified the optimum value of alpha to create a grade model which best predicts the probability of completed Port stockpiles being within customer acceptable range (Everett, 2001; Everett and Kamperman, 1999).

\section{Total Grade Stress}

Grade stress can be defined as the normalised deviation from shipping target relative to predetermined tolerances. These tolerances can be adjusted to increase emphasis on the more critical control components of the ore. Stress $(\mathrm{St})$ is defined as A/ B in Figure 5. 


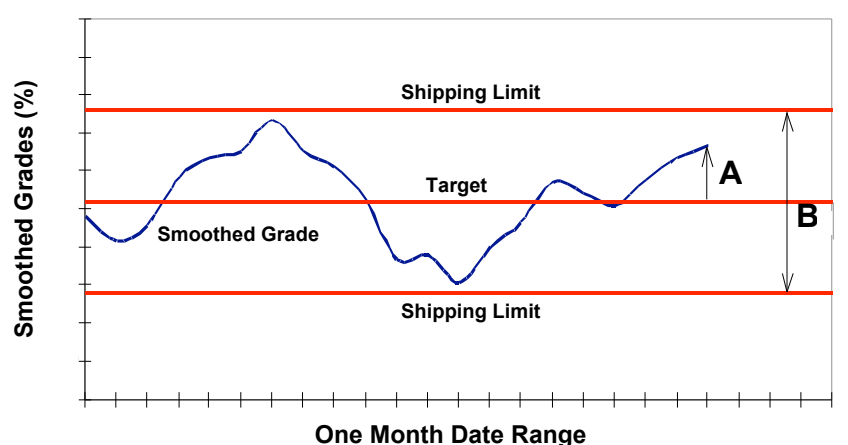

Figure 5. Explanation of grade stress.

The Total Grade Stress is defined as:

$$
\mathrm{St}_{\text {Total }}=\left\{\left(\mathrm{StFe}^{2}\right)^{2}(\mathrm{StP})^{2}+\left(\mathrm{St}_{\mathrm{SiO}_{2}}\right)^{2}+\left(\mathrm{St}_{\mathrm{Al} 2 \mathrm{O}_{3}}\right)^{2}\right\}
$$

Total Grade Stress is therefore a single objective function which can be minimised by relatively simple computational techniques in order to achieve optimum quality.

In addition, the use of Total Grade Stress facilitates an automatic graded response to deviations from target because of the squared functions in the equation. This contrasts to the "black-and-white" response in the batch system, ie no response for grade anywhere within target range and total response for grade anywhere outside the target range.

\section{The Continuous Stockpile Model}

The Continuous Stockpile Model is central to the short term scheduling decision support system. It is comprised of the exponentially smoothed grade for each of the four control components (Fe, P, SiO2 and $\mathrm{Al} 2 \mathrm{O} 3$ ), taking into account all inprocess ore and most recent bias.

The aim of the short term scheduling decision support system is to keep the Continuous Stockpile Model for each component within limits around the monthly mine target (Figure 6).

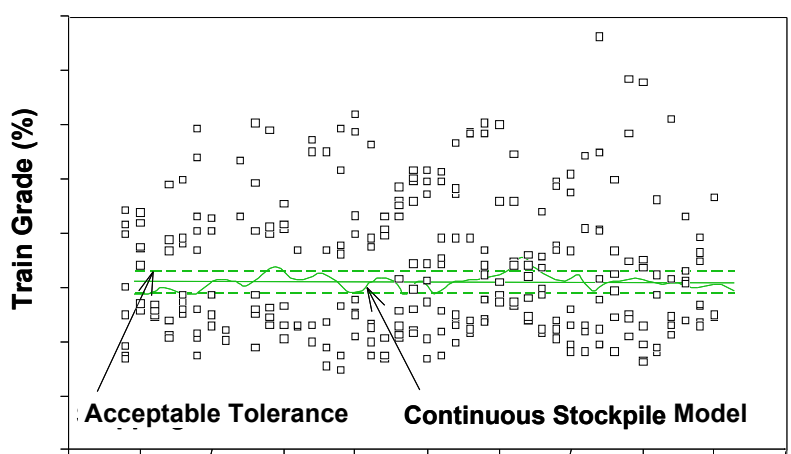

Two Month Date Range

Figure 6. Example of the Continuous Stockpile Model.

Through simulation and now by experience, if this is achieved, there is a high probability that Port stockpiles built from the material in the time frame will be within the acceptable limits provided the CSMS rules are maintained.
The smoothing component of the model also allows for the appropriate response to be made at the Mine to trends in grade, taking into account the precision of the sampling system and bias trends.

\section{Port}

The Continuous Stockpile Model has significantly contributed to the decoupling of the Mine and Port operations while maintaining a high probability that Port stockpiles will be within shipping tolerances. The Port can start or stop a stockpile independent of any Mine operations provided the CSMS rules are adhered to.

\section{Train unloading}

To achieve reliable decoupling, the time sequence of ore through the system needs to be maintained to the completion of Port stockpiling. To this end, priority is given to dumping trains in the same sequence that they depart the Mine. In practice this is achieved $97 \%$ of the time. Before the introduction of the CSMS typically only $85 \%$ of trains were dumped in sequence.

\section{Stockpiling}

Stockpiling at the Port is the main step in the process where short term variability is blended to an acceptable range.

All stockpiles are built utilising chevron stacking with ply extensions. Priority is given to building them to completion in the same sequence as the rakes departed the Mine without diversions.

To achieve acceptable short term variability the size of stockpiles is important. Simulation studies showed that a quantitative relationship exists between stockpile size and reduction of short term variability. Inter-stockpile variability was used as the output indicator in the simulation study (Figure 7).

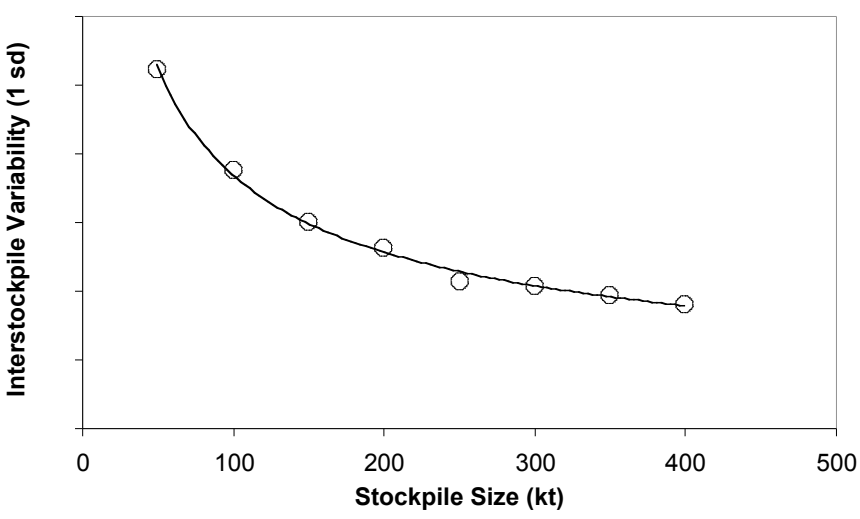

Figure 7. Relationship between stockpile size and inter-stockpile variability as determined by simulation.

At the time of the study, the Port had a significant number of stockpiles below $100 \mathrm{kt}$ and above $250 \mathrm{kt}$.

Results showed that stockpile variability increased significantly for stockpiles below about $100 \mathrm{kt}$ and that there is only a small improvement in short term variability for stockpiles above $250 \mathrm{kt}$. 
It was concluded that the benefits of larger stockpiles are not nearly as great as might be intuitively thought, and that avoiding building of small stockpiles was the highest priority step in order to reduce the risk of off-grade stockpiles. Consequently the stockpile yard layout was redesigned incorporating stockpiles in the range of 200 to $225 \mathrm{kt}$ in the high turnover areas (Figure 8). Some medium size stockpiles are unavoidable to accommodate circumstances where product clashes occur when loading two ships simultaneously with one product.

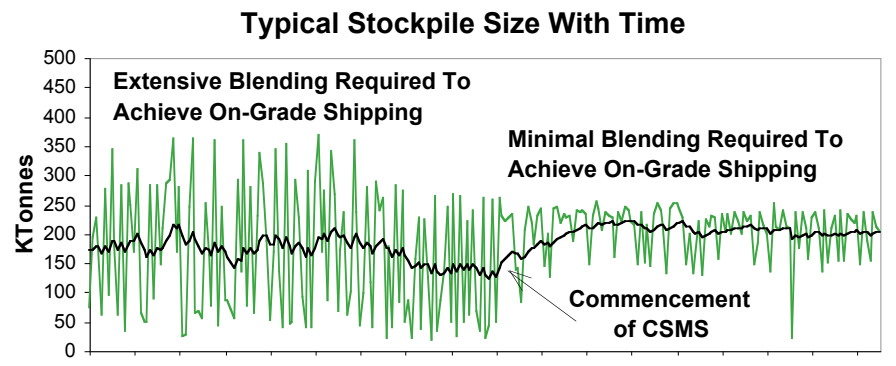

Typical Stockpile Grade Variability With Time

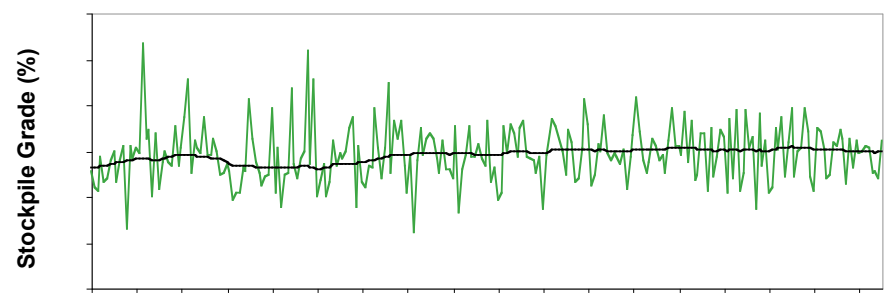

Eighteen Months Date Range

Figure 8. Comparison of stockpile characteristics and quality before and after the introduction of CSMS.

Since the introduction of CSMS, results from stockpiles have confirmed the simulation results.

Since the introduction of CSMS only $6 \%$ of the stockpiles have been blended for grade reasons to ensure shipment grades within customer acceptable ranges. Previously $26 \%$ blending of stockpiles was carried out to achieve the same result.

\section{Reclaiming and shiploading}

Since the introduction of CSMS a priority is placed on reclaiming stockpiles as three benches with pilgrim steps aligned to the size of the shipment to ensure a representative percentage of each bench is included in each shipment.

Stockpiles are now reclaimed to completion without diversion for grade reasons.

Intra-stockpile variability does not significantly affect short term variability within shipments if the stacking and reclaiming procedures are followed (Robinson, 2001).

Although sub-gross samples of cargoes are taken, no action results for grade reasons as a result of any of these sub-gross grades.

The introduction of CSMS, together with a focussed operational efficiency program, has contributed to a significant increases in shiploading rates (Figure 9).

No shipments have been outside the customer acceptable range since the commencement of CSMS. It has been demonstrated that there has been no significant statistical increase in shipment variability (Everett, 2002).

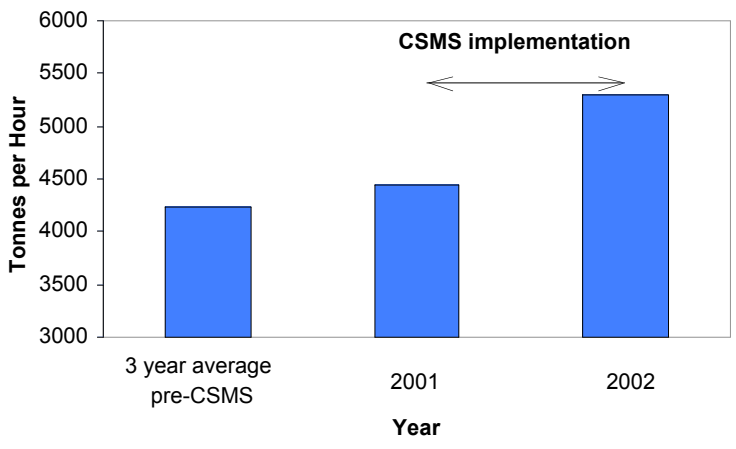

Figure 9. Port operations gross loading rates as a function of time.

\section{Management review}

Three major management review processes drive the CSMS:

- An integrated monthly meeting reviewing tonnage and grade compared to targets is conducted by all senior operations managers and marketing personnel. At this meeting operations managers are held accountable for achieving the previous targets and an agreements is reached on next months' targets which are then fixed throughout the entire process for the month.

- A daily review of the Continuous Stockpile Model grades is conducted during the Operations Conference Call between all sites, which includes all senior operations management and key personnel from mine, rail and port.

- If a stockpile grade falls outside monthly tolerances it is referred to senior operations management to determine appropriate action.

\section{CONCLUSIONS}

The BHP Billiton Yandi CSMS has demonstrated that:

- High production rates and quality control are achieveable in a fully integrated system where decision making on grade is focussed on the correct steps in the process.

- The utilisation of exponential smoothing and grade stress allow for complex and large data sets to be processed and provides real time decision support utilising the most accurate data available at the time.

- Control measures of long term and short term variability are different and should not be confused within the process.

- Use of the Continuous Stockpile Model has allowed effective operational decoupling within the process and has enabled increased efficiencies.

- The continued active participation of senior operations management has allowed for the innovative approach to become embedded within the operations.

\section{ACKNOWLEDGEMENTS}

The authors wish to thank the management of BHP Billiton Iron Ore Pty Ltd for permission to publish this manuscript. Special 
thanks go to internal company reviewers and conference reviewers whose recommendations are gratefully acknowledged.

\section{REFERENCES}

Everett, J.E., 2001. Iron ore production scheduling to improve product quality. European Journal of Operational Research, 129, 355-361.

Everett, J.E., 2002. Ship and customer analysis ("ShipCanal”). Internal BHP Billiton report 0202/3, 15 March 2002.

Everett, J.E. and Kamperman, M., 1999. A simulation model of iron ore production sequencing to achieve uniform blend, in Proceedings of the International Conference on Industrial Logistics, 337-345. St Petersburg, Russia, ICIL '99.

Hanke, J. E., \& Reitsch, A.G., 1998. Business Forecasting. Sixth ed. Englewood Cliffs, NJ: Prentice-Hall.

Robinson, G, 2001. June 2001 review of BHP Iron Ore's blending practices. Internal BHP Billiton report 01/167, 15 October 2001. 